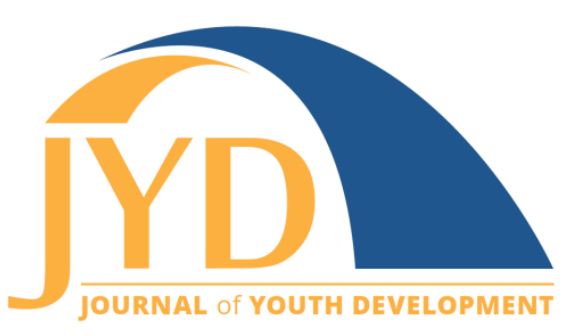

http://jyd. pitt. edu/ | Vol. 13 Issue 3 DOI 10.5195/jyd.2018.606 | ISSN 2325-4017 (online)

\title{
Lessons Learned from an After-School Program: Building Personal and Social Responsibility
}

\author{
Victoria Nicole Ivy \\ University of Alabama \\ vnshiver@crimson.ua.edu \\ K. Andrew R. Richards \\ University of Alabama \\ karichards2@ua.edu \\ Michael A. Lawson \\ University of Alabama \\ malawson1@ua.edu \\ Tania Alameda-Lawson \\ University of Alabama \\ talamedalawson@ua.edu
}

\begin{abstract}
Drawing from the physical activity and positive youth development literatures, this paper describes a novel after-school effort designed to enhance youths' life skill development outcomes across school, family, and community settings. This program, which is derived from the Teaching Personal and Social Responsibility (TPSR) model, is a university-assisted effort serving $1^{\text {st }}$ through $5^{\text {th }}$ graders attending a low-income elementary school. As a part of this model's approach, pre-service physical education teachers engage in a yearlong course sequence and practicum that enables them to deliver the program. University graduate students and faculty then provide ongoing support, facilitation, and training to the pre-service teachers at the same time they conduct field-based research on the effort. The preliminary data indicate that the program can successfully impact several teaching and life skill development outcomes. However, additional interventions appear to be needed to extend youths' outcomes to settings outside of the program.
\end{abstract}

Key words: after-school program, teaching personal and social responsibility, youth from communities affected by poverty, sport-based youth development programs, physical activity

(c) $\mathrm{EY}_{\mathrm{EY}}$ New articles in this journal are licensed under a Creative Commons Attribution 4.0 License. This journal is published by the University Library System, University of Pittsburgh and is cosponsored by the University of Pittsburgh Press. The Journal of Youth Development is the official peer-reviewed publication of the National Association of Extension 4-H Agents and the National AfterSchool Association. 


\section{Building Personal and Social Responsibility}

Positive youth development (PYD) programs provide youth with important competencies they can use to prepare for successful life futures. After-school efforts represent common targets for PYD programming because they provide ease of access to youth attending school. After-school programs are also likely structured in ways that enable youth to pursue their emergent strengths, interests, and identity beliefs more than what is often possible during the formal school day (Weisman \& Gottfredson, 2001). It has been suggested that the hours immediately following school are critical for providing youth programming in order to provide an environment meant for constructive progress as opposed to potential delinquent behaviors due to lack of youth supervision.

One important strand of PYD programming that has emerged in recent years is called sportbased youth development (SBYD; Holt et al., 2017). SBYD efforts typically utilize physical activity as the primary mechanism for teaching youth an important set of life skills (e.g., role modeling, goal setting, self-accountability, team building, etc.). These life skills are prioritized in service of two related purposes. The first purpose is to enhance student knowledge and use of skills and competencies that can improve their overall health and experiences with others in the program. The second purpose is to provide youth with the opportunity to understand how the skills they learn in PYD programs can be transferred to home, school, and community settings (Gordon \& Doyle, 2015), though there is limited research on transfer promotion strategies.

Although research has documented how SBYD programs can help youth develop life skills associated with personal and social responsibility (e.g., Armour \& Sandford, 2013), the need remains for additional practice-embedded research and descriptions of different models, approaches, and settings. This article is designed to attend to this need.

At the heart of our analysis is a university-assisted, SBYD program that is implemented during after-school time in an elementary school that serves a community affected by poverty. This effort, which is modeled principally after the best practice curriculum called Teaching Personal and Social Responsibility (TPSR; Hellison, 2011), has two defining features in addition to PYD. One of these features is the use of preservice physical education teachers as activity leaders (ALs). Another concerns the program's primary goal of helping youth transfer skills they gain through the program to outside environments.

Each of these areas of program development—PYD, training preservice teachers, and facilitating transfer-requires detailed scholarly attention. Our analysis here is intended to provide an overview of experiences and lessons learned. Accordingly, we begin with a description of the 


\section{Building Personal and Social Responsibility}

TPSR program model before providing additional insight into the strengths, opportunities, and challenges associated with developing and implementing a multi-pronged approach to PYD in after-school contexts.

\section{Overview of Teaching Personal and Social Responsibility Model}

TPSR is a best-practice model for the teaching and training of physical education students. The model is based on the assumption that positive personal and social development in youth is not automatic; it must be fostered deliberately through systematic intervention approaches. Physical activity is the primary driver of TPSR programming because it is viewed as an instrumental facilitator for particular social roles and interactions and enables youth to practice social skills such as losing gracefully and tactfully communicating their thoughts and feelings (Gordon \& Doyle, 2015).

The TPSR model is designed to achieve five primary goals (see Table 1). These include the personal responsibility goals of participation, effort, and self-direction, and the social responsibility goals of respect and caring for others. The ultimate goal of the model is to help youth learn how to transfer these competencies to other areas of their lives. Goals are not introduced in a prescriptive manner but are instead tailored to meet youth needs each session through the application of a flexible lesson format (Hellison, 2011). For example, if a previous session focused on self-direction but many students chose not to participate, the next session may focus on participation. This method enables program leaders to adapt the model to fit particular organizational contexts without straying from the TPSR characteristics (Gordon, Jacobs, \& Wright, 2016).

Each TPSR lesson begins with relational time. Relational time is structured so that youth in the program have meaningful opportunities to develop positive relationships with peers and the ALs. The awareness talk follows. It includes a brief discussion of the TPSR goal that is emphasized in that particular lesson. The lesson focus constitutes the majority of each program session. It consists of learning physical activity skills while also providing youth opportunities to practice the selected goal for the day. The group meeting is a collective debriefing session in which youth consider how the group performed relative to the TPSR goal for the day. Each TPSR session then ends with group and individual reflection time. During this time, children have a role in self-assessment and peer assessment (Escartí, Wright, Pascual, \& Gutiérrez, 2015). Specifically, they consider their individual and collective performance and have the opportunity to share those reflections. 
Table 1. The Five TPSR Goals and Their Meaning

\begin{tabular}{|l|l|}
\hline Goal & Meaning \\
\hline Respect & Youth control their behavior so that they do not inhibit others' right to learn. \\
\hline Participation and effort & $\begin{array}{l}\text { Participation indicates a willingness to take part in the activity or discussion. } \\
\text { Effort indicates a desire to face challenges and overcome adversity. }\end{array}$ \\
\hline Self-direction & $\begin{array}{l}\text { Youth begin to identify their own needs and work without direction } \\
\text { supervision. }\end{array}$ \\
\hline Caring for others & $\begin{array}{l}\text { A cooperative goal in which youth lend support, show concern, and help } \\
\text { others when it is desired. }\end{array}$ \\
\hline Transfer & $\begin{array}{l}\text { Using each of the previous goals in a setting outside of the program such as } \\
\text { the school, home, or community. }\end{array}$ \\
\hline
\end{tabular}

Note. Adapted from Hellison (2011)

Throughout this general lesson format, the ALs' involvement is based on several key requirements. This includes the expectations that ALs (a) provide youth with consistent opportunities to make choices and exercise their voices; (b) reflect frequently on their own practice; (c) encourage youth to honestly disclose and learn from their mistakes, which requires ALs to discuss negative behaviors with youth and develop a plan for positive change rather than using punishment; (d) incorporate the TPSR responsibility goals into physical activities and discussions; and (e) take a humanistic approach by making a consistent effort to create caring social interactions to enhance emotional safety in the program (Hellison, 2011).

\section{Program Setting and Activity Leader Training}

Our TPSR program operates 3 days a week for 30 weeks during the school year in an elementary school that serves 450 youth in a community that is challenged by poverty. Approximately $85 \%$ of youth attending the school are underrepresented ethnic minorities, and $90 \%$ are eligible for free and reduced lunch. On average, 70 youth participate in the program and are referred by school staff based on academic (e.g., consistently low grades), behavioral (e.g., infractions resulting in administrative discipline during the school day), and/or socioemotional needs (e.g., limited ability to navigate healthy relationships with others). 


\section{Building Personal and Social Responsibility}

Program activity is facilitated by dividing the youth into two groups that are organized by grade level. The first group consists of third, fourth, and fifth grade students, and the second includes first and second grade students. Each group rotates between two 1-hour strands of program activity: (a) TPSR SBYD; and (b) school-based academic enrichment that is unrelated to the SBYD.

The ALs facilitate the program as part of the field experiences built into two consecutive undergraduate courses focused on teaching elementary physical education. All physical activity content is framed through the skill themes approach (Graham, Holt-Hale, \& Parker, 2013), which is a developmentally appropriate progression for teaching fundamental movement skills. During the first semester, the ALs spend the first 5 weeks on campus learning about appropriate teaching practices. The AL's learn the TPSR model through reading and discussing the Teaching Responsibility through Physical Activity textbook (Hellison, 2011), observing example lessons, and peer teaching.

Following the initial 5 weeks, the ALs begin working in the elementary school. ALs are divided into teaching pairs, which allows for one lead and one assistant teacher for each lesson. Each teaching team typically works with a small group of 10 to 15 youth. The small groups facilitate more intensive social interactions between youth and ALs, and these interactions help ALs to develop more personalized relationships. In the first semester, ALs teach two 1-hour lessons a week with a weekly 1-hour, on-campus seminar. Content taught during the first semester focuses on basic movement skills, dance, and gymnastics activities.

In the second semester, ALs teach fundamental movement skills that lead into organized activities, such as throwing and kicking. In contrast to the first semester, the ALs have the flexibility to select activities to teach the content. This allows them to consider activity selection in relation to students' needs and interests. During the second semester the ALs spend 4 hours at the program each week, two teaching and two observing their peers, combined with a weekly 2-hour on-campus debrief session. The additional time in the second semester is due to a higher credit hour course and facilitates peer feedback. Specifically, ALs are trained to use the Tool for Assessing Responsibility-Based Education (TARE) 2.0 (Escartí, et al., 2015) systematic observation instrument to code their peers' teaching of TPSR.

It should be noted that we handpick the general physical activity content to be taught across both semesters. The physical activity content is selected to challenge the ALs progressively by adding equipment manipulation over time. The majority of physical activity skills are novel to 


\section{Building Personal and Social Responsibility}

the program youth and receive mixed levels of interest. One limitation of this approach is that it confines youth choices and voices, though ALs are expected to integrate student voice into the design and development of their lesson plans.

During both semesters of the program, the ALs complete what are called critical incident reflections (Curtner-Smith, 1996) immediately after teaching and then complete more in-depth reflections at the end of each week. These reflections enable the ALs to document and keep an ongoing record of the developments that occur during each lesson. As a part of their weekly reflections, ALs are asked more targeted questions about how they can enhance their practice and pedagogy around the TPSR model. For example, ALs may respond to the following prompt, "What goals do you have for building relationships with youth in the next several weeks?" Finally, the ALs are videotaped during teaching episodes and asked to complete the TARE 2.0 while watching their own teaching.

\section{The After-School Program: Implementing Teaching Personal and Social Responsibility}

Each after-school session is organized according to the TPSR model format. During the relational time (5 minutes) the AL's play music and allow youth to choose equipment (e.g., basketball, jump rope) for play. The ALs make a point to join in the youth-selected activities and connect with them by talking about their hobbies, families, and other potential personal connections. This is designated relationship-building time, though relationship building is also integrated throughout the entirety of each session. Youth then break into their groups led by the ALs.

In each group, the 5-minute awareness talk begins and the ALs introduce the TPSR goal for the day. (e.g., leadership). The ALs lead discussions framed by asking questions such as "What is leadership?" For example, the youth may say it is "being an example to others." Although some youth raise their hands more often, the small group size facilitates the active engagement of most youth on most days. For the first 3 weeks, we prescribe the TPSR goals used by the ALs. From that point forward, the ALs select the TPSR goal that they think is the most appropriate for their group.

The 35-minute lesson focus intertwines the TPSR goal with the physical activity in order for personal and social responsibility to be explicitly practiced and discussed through authentic 


\section{Building Personal and Social Responsibility}

experiences (Hellison, 2011). For example, during an early module focused on line dancing, we direct the ALs to encourage leadership development by creating groups of four, having each member in each group learn a different set of eight counts, and then teach their eight counts to their small group. Feedback is provided by the ALs throughout the session to support the development of youth leadership skills. The integration of TPSR is often a challenge for individuals and must be practiced intentionally.

Toward the end of the lesson, ALs lead 5- to 10-minute lesson closures in their small groups that incorporate the individual and group reflection elements of TPSR. At this point, each group discusses their overall performance and ideas for improvement. For example, if youth experience difficulty staying on task, the goal for the following session may be to remind one another to focus. Self-reflection is then facilitated by asking youth to reflect on their own performance by indicating with their thumbs their degree of satisfaction with their own behavior. This "thumbometer" approach (Hellison, 2011) encourages youth to give a thumb up if they achieved the goal, a thumb to the side if partially achieved, and a thumb down if not achieved. As a part of this evaluation, youth are encouraged to offer suggestions about how the lesson might be improved and to identify goals for performance improvement.

Last, at the end of the lesson reflection process, the ALs facilitate a discussion on transfer. For example, following a lesson on leadership, questions may include: "How can you show leadership during the school day? At home?" Typically, children respond by giving vague answers, such as "be nicer." In such cases, the ALs ask follow-up questions that promote deeper reflection, such as, "How will you be nicer?" It is understood, however, that the environments experienced outside of the program share different expectations for youth, which can make it difficult to transfer TPSR goals as they are taught (Gordon \& Doyle, 2015). Toward this end, we encourage ALs to learn about the communities in which their children live to better facilitate these conversations and find ways goals can be transferred safely and appropriately (Jacobs, Lawson, Ivy, \& Richards, 2017).

\section{Key Project Developments and Lessons Learned}

Since beginning the TPSR program, our research team has been studying facilitators and barriers to optimal program implementation to increase understanding and improve our implementation of the model and share lessons learned. This research has focused on the ways the program helps ALs develop skills they need to successfully implement the TPSR model and identifying the practices needed to help youth develop life skills, as well as transfer of those 


\section{Building Personal and Social Responsibility}

skills. Our initial analyses have been conducted using data primarily collected from ALs, including autobiographical essays (Betourne \& Richards, 2015), individual interviews, daily critical incident reflections after teaching, informal interviews during program session, participant observation, and document analysis (e.g., lesson plans).

The early results of this research indicate that several ALs struggled initially with the TPSR model and found it difficult to adopt its associated teaching philosophy. As is typical of physical education recruits, many ALs had experienced a very authoritative approach to teaching in their own K-12 physical education classes and would initially resort back to teacher-centered strategies (Curtner-Smith, 2017). Initial teaching struggles include behavior management, teaching skills (i.e., smooth transitions), and navigating the challenges of working with children of color from an area that differs from the lived realities of many ALs. The majority of ALs grew up in middle-class, predominantly white settings, and have struggled or made little attempt to understand the culture of the youth in the program.

Over time, several ALs came to realize that humanistic approaches for instructing and managing behavior were more effective. They began to understand the value of using physical activity as a means through which to teach life skills, and began to address the teaching struggles encountered through the program by taking responsibility for their role in structuring lessons rather than blaming youth for misbehavior. Many found that developing relationships and understanding the challenges the youth face outside of the program were key to making more meaningful connections. For example, when several ALs learned that several youth did not live with their nuclear family, they used language describing the use of goals at home to better fit all home situations.

While most of our current research agenda has focused on the ALs learning to use TPSR, observational data indicate that youth enjoy the program and have begun to internalize the first four TPSR goals. For example, our field notes from program observations indicate that youth are consistently able to describe what each goal means and provide examples of how they have met goals in the program. In our view, these data points stand as important preliminary markers of program progress, and we plan to expand our research agenda to include the voices of the youth, their families, and school personnel in future studies. 


\section{Building Personal and Social Responsibility}

\section{Program Improvement Targets and Challenges}

Although the data lend some support to the effectiveness of the program experience in assisting the development of the ALs and select program youth, our data do not indicate that we are achieving our targeted goal of helping youth regularly transfer the competencies they gain to settings outside of the gym. One potential reason for this challenge is that the program has yet to develop a meaningful mechanism that can help youth reconcile some of the value conflicts that exist between and within their various social worlds. Our observational data have repeatedly uncovered inconsistencies in expectations for youth behavior across settings, which may limit the transferability of lessons learned in the program (Jacobs et al., 2017).

To this point, a future research and development priority is to gain better insight into how the norms promoted in the program setting might differ from those in youths' classroom, peer, and community ecologies. For instance, in the program setting, youth are encouraged to act autonomously. When behavioral or social difficulties arise, the ALs are encouraged to take the time to help children reflect on their behaviors in ways that minimize the need for traditional forms of punishment. In the school setting, however, youth seldom select their desired learning activities; they are typically allowed to talk only when they are called upon, and when behavioral difficulties arise, they are frequently disciplined by being sent to the principal's office. Conversations with children and school staff have indicated that these same conflicts appear to exist between TPSR program norms and behavioral preferences exhibited in some peer and family ecologies. We have learned, for example, that parents/caregivers often encourage youth to protect themselves physically and, at times, aggressively in order to garner respect from their peers.

When these norms and value conflicts are present, it makes it very difficult for youth to figure out how they might transfer the competencies they gain from the TPSR program to other areas of their lives. To wit, this difficulty persists because the norms for expected conduct between settings appear to be more different and competing than they are similar (Jacobs \& Wright, 2018). As a result of this mismatch, additional programmatic interventions and supports are needed, especially those that target change in institutional and family-level practices (Lawson, Alameda-Lawson, \& Richards, 2016). 


\section{Implications for Practice}

The TPSR model, as conceived and implemented in our after-school program, has yielded several teaching and learning outcomes. However, the program may require additional interventions that extend beyond the boundaries of a single after-school program to achieve long-term outcomes. For this reason, the next generation of PYD programs may benefit by nesting the kind of stand-alone programs described in this article with broader collective impact efforts that help program developers and other school-community leaders better synchronize and harmonize youth ecologies. For example, a TPSR-based program could be integrated along with parent and community engagement programs such as including community mentors and/or local youth organizations or partners. Another seemingly clear but often overlooked conglomerate is with the school and school district. Each setting can integrate the TPSR model and goals, therefore promoting similar messages across contexts and, expectantly, providing youth with a deeper level of understanding (Gordon \& Doyle, 2015).

Beyond these aims, our data indicate that stand-alone after-school programs can benefit by incorporating teacher education and training into the daily structure and routine of SBYD (Richards, Ivy, Lawson, \& Alameda-Lawson, 2018). The effective use of TPSR requires topdown, teacher-centered models of teaching to be practiced in order to facilitate the type of student-centered processes targeted in TPSR. Practice is essential, and our work indicates that teacher education programming represents one viable avenue for creating the next generation of professionals for PYD programs as well as a partnership between universities and afterschool programs.

Another consideration is that SBYD provides an avenue towards enhancing youths' physical activity. This is important due to the recommendation that children and adolescents take part in moderate to vigorous physical activity for 60 minutes each day (Sallis, Carlson, \& Mignano, 2012). Within programs, ALs' encouragement of and participation in physical activity can motivate youth participants to enhance their physical health (Huberty, Beets, Beighle, \& McKenzie, 2013). Thus, in combination with the TPSR model, programs may use pedometers to boost moderate to vigorous physical activity or could focus on teaching children the importance of meeting and measuring their target heart rate regularly.

Practicing movement during program time, similar to practicing the TPSR components, may result in transfer of skills learned to outside settings (Bean, Kendellen, \& Forneris, 2016). As youth gain awareness for the best way to pursue and achieve fitness goals and outcomes, they 


\section{Building Personal and Social Responsibility}

become prepared for a life of physically healthy choices. When that same concept is applied within the TPSR model and personal and social responsibility, youth are prepared for a life of healthy socioemotional choices. Thus, health for the whole body, physically and mentally, may be achieved through the use of activity within the TPSR model.

An important strategy for all PYD programs to follow in order to achieve health for the whole body is to provide professional development training for their staff (Durlak, Weissberg, \& Pachan, 2010). All staff should develop skills with the help of an expert in the area of physical activity and the TPSR model. If taking on a leadership role among youth within a program, it is important that individuals maintain exceptional interpersonal skills and are capable of understanding and working with the developmental abilities that are present. An understanding of and comfort within the program culture and in presenting knowledge in a sequential and beneficial format is also necessary.

Unfortunately, staff frequently incorporate activities that limit moderate to vigorous physical activity by including long lines (e.g. waiting to climb a rope) and elimination activities (e.g. musical chairs), and rarely promote physical activity in general (Weaver et al., 2015). Staff training has been found to be one of the greatest challenges faced in providing program opportunities for youth (Herrera \& Arbreton, 2003) and staff are frequently unprepared to incorporate TPSR appropriately (Forneris, Whitley, \& Barker, 2013). One way to ensure that the appropriate skills are developed and utilized is for PYD programs to partner with university faculty. This partnership can be mutually beneficial as the members and participants within the programs present and receive positive accurate programming and the faculty members may further develop scholarship related to the field. This is also another example of how a program can be nested in a collective effort concerning child health and development.

The National AfterSchool Association has indicated that participants need to fulfill the Center for Disease Control recommendations for daily physical activity (CDC, 2015); staff need to be trained in evidence-based models and content, and the social environment must encourage positive relationships and appropriate comfortable community settings (NAA, 2011). The methods provided within this program description specify an example of practice that meets the NAA standards and promotes positive results among participating youth. Also, developing meaningful, site-embedded professional development programming represents a critical avenue for spreading TPSR and related SBYD models to new settings and populations as those trained may continue on in alternative situations. This article was developed in support of these 
Journal of Youth Development | http://jyd.pitt.edu/ | Vol. 13 Issue 3 DOI 10.5195/jyd.2018.606

Building Personal and Social Responsibility

possibilities and with the hope that future research-practice partnership efforts will benefit from the lessons learned from our initial pilot work.

\section{References}

Armour, K., \& Sandford, R. (2013). Positive youth development through an outdoor physical activity programme: Evidence from a four-year evaluation. Educational Review, 65, 85-108. doi: 10.1080/00131911.2011.648169

Bean, C., Kendellen, K., \& Forneris, T. (2016). Moving beyond the gym: Exploring life skill transfer within a female physical activity-based life skills program. Journal of Applied Sport Psychology, 28(3), 274-290. doi: 10.1080/10413200.2015.1124155

Betourne, J. A., \& Richards, K. A. R. (2015). Using autobiographical essays to encourage student reflection on socialization experiences. Journal of Physical Education, Recreation and Dance, 86(2), 34-40. doi: 10.1080/07303084.2014.988376

Centers for Disease Control and Prevention. (2015). Childhood and adolescents physical activity recommendations. Retrieved from https://www.cdc.gov/physicalactivity/basics/children/index.htm

Curtner-Smith, M. (1996). The impact of early field experience on preservice physical education teachers' conceptions of teaching. Journal of Teaching in Physical Education, 15, 224-250. doi: 10.1123/jtpe.15.2.224

Curtner-Smith, M. (2017). Acculturation, recruitment, and the development of orientations. In K.A. R. Richards \& K. L. Gaudreault (Eds.), Teacher socialization in physical education: New perspectives (pp. 33-46). New York, NY: Routledge.

Durlak, J. A., Weissberg, R. P., \& Pachan, M. (2010). A meta-analysis of after-school programs that seek to promote personal and social skills in children and adolescents. American Journal of Community Psychology, 45(3-4), 294-309. doi: 10.1007/s10464-010-9300-6

Escartí, A., Wright, P. M., Pascual, C., \& Gutiérrez, M. (2015). Tool for Assessing Responsibility-based Education (TARE) 2.0: Instrument revisions, inter-rater reliability, and correlations between observed teaching strategies and student behaviors. Universal Journal of Psychology, 3(2), 5563. doi: $10.13189 /$ ujp.2015.030205

Forneris, T., Whitley, M. A., \& Barker, B. (2013). The reality of implementing community-based sport and physical activity programs to enhance the development of underserved youth: Challenges and potential strategies. Quest, 65(3), 313-331. doi: 10.1080/00336297.2013.773527

Gordon, B., \& Doyle, S. (2015). Teaching personal and social responsibility and transfer of learning: Opportunities and challenges for teachers and coaches. Journal of Teaching in Physical Education, 34(1), 152-161. doi: 10.1123/jtpe.2013-0184 


\section{Building Personal and Social Responsibility}

Gordon, B., Jacobs, J. M., \& Wright, P. M. (2016). Social and emotional learning through a teaching personal and social responsibility based after-school program for disengaged middle-school boys. Journal of Teaching in Physical Education, 35(4), 358-369. doi: 10.1123/jtpe.2016-0106

Graham, G., Holt-Hale, S., \& Parker, M. (2012). Children moving: A reflective approach to teaching physical education ( $9^{\text {th }}$ ed.). New York, NY: McGraw Hill.

Hellison, D. (2011). Teaching responsibility through physical activity. Champaign, IL: Human Kinetics.

Herrera, C., \& Arbreton, A. J. A. (2003). Increasing opportunities for older youth in after-school programs: A report on the experiences of Boys \& Girls Clubs in Boston and New York City. Philadelphia, PA: Public/Private Ventures.

Holt, N. L., Neely, K. C., Slater, L. G., Camiré, M., Côté, J., Fraser-Thomas, J., \& Tamminen, K. A. (2017). A grounded theory of positive youth development through sport based on results from a qualitative meta-study. International Review of Sport and Exercise Psychology, 10, 1-49. doi: 10.1080/1750984X.2016.1180704

Huberty, J. L., Beets, M. W., Beighle, A., \& Mckenzie, T. L. (2013). Association of staff behaviors and afterschool program features to physical activity: Findings from Movin' After School. Journal of Physical Activity and Health, 10(3), 423-429. doi: 10.1123/jpah.10.3.423

Jacobs, J. M., Lawson, M., Ivy, V. N., \& Richards, K. A. R. (2017). Enhancing the transfer of life skills from sport-based youth development programs to school, family, and community settings. Journal of Amateur Sport, 3(3), 20-43. doi: 10.17161/jas.v3i3.6514

Jacobs, J. M., \& Wright, P. M. (2018). Transfer of life skills in sport-based youth development programs: A conceptual framework bridging learning to application. Quest, 70(1), 81-99. doi:10.1080/00336297.2017.1348304

Lawson, M. A., Alameda-Lawson, T., \& Richards, K. A. R. (2016). A university-assisted, place-based model for enhancing students' peer, family, and community ecologies. Education Sciences, 6(16), 1-15. doi:10.3390/educsci6020016

National AfterSchool Association. (2011). HEPA Standards. Retrieved from https://naaweb.org/images/NAA_HEPA_Standards_new_look_2015.pdf

Richards, K. A. R., Ivy, V. N., Lawson, M. A., \& Alameda-Lawson, T. (2018). Teaching personal and social responsibility in physical education teacher education. In T. D. Meidl \& M. S. Dowell (Eds.), Handbook of research on service-learning initiatives in teacher education programs (pp. 143162). Hershey, PA: IGI Global.

Sallis, J. F., Carlson, J. A., \& Mignano, A. M. (2012). Promoting youth physical activity through physical education and after-school programs. Adolescent Medicine: State of the Art Reviews, 23(3), $493-$ 510. 
Journal of Youth Development | http://jyd.pitt.edu/ | Vol. 13 Issue 3 DOI 10.5195/jyd.2018.606 Building Personal and Social Responsibility

Weaver, R. G., Beets, M. W., Huberty, J., Freedman, D., Turner-Mcgrievy, G., \& Ward, D. (2015). Physical activity opportunities in afterschool programs. Health Promotion Practice, 16(3), 371-382. doi: $10.1177 / 1524839914567740$

Weisman, S. A., \& Gottfredson, D. C. (2001). Attrition from after school programs: Characteristics of students who drop out. Prevention Science, 2(3), 201-205. doi: 10.1023/A:1011515024809 